\title{
High prevalence of diagnosis of diabetes, depression, anxiety, hypertension, asthma and COPD in the total population of Stockholm, Sweden - a challenge for public health
}

Axel C Carlsson ${ }^{1,2^{*}}$, Per Wändell ${ }^{1}$, Urban Ösby ${ }^{3,4}$, Ramin Zarrinkoub ${ }^{1,5}$, Björn Wettermark ${ }^{5,6}$ and Gunnar Ljunggren ${ }^{5,7}$

\begin{abstract}
Background: There is limited knowledge on the prevalence of disease in total populations. Such studies have historically been difficult to conduct but the development of health data registers has facilitated large-scale studies on recorded diagnoses in entire regions. The aim of this study was to analyze the prevalence of diagnosis of six common diseases in the Swedish capital region.
\end{abstract}

Methods: The study population included all living persons who resided in Stockholm County, Sweden, on December 31 2011 ( $N=2093$ 717). Information on all consultations between 2007 and 2011 was obtained from primary health care, specialist outpatient care and inpatient care. Prevalence was defined as the proportion of individuals with a recorded diagnosis of diabetes, depression, anxiety disorders, hypertension, asthma and chronic obstructive pulmonary disease during the five year period, respectively. Analyses were done by age and gender.

Results: Hypertension had the highest five-year prevalence (12.2\%), followed by depression (6.6\%), diabetes mellitus (6.2\%), asthma (5.9\%), anxiety disorders/phobia (4.8\%), and COPD (1.8\%). Diabetes was more common in men (5.3\% of women and $7.1 \%$ of men) while depression ( $8.7 \%$ in women and $4.4 \%$ in men) and anxiety (6.3\% in women and $3.4 \%$ in men) were considerably more common in women. Smaller gender differences were also found for hypertension (13.0\% in women and $11.4 \%$ in men), asthma (6.4\% in women and $5.4 \%$ in men) and COPD (2.1\% in women and $1.6 \%$ in men). Diabetes, hypertension and COPD increased markedly with age, whereas anxiety, depression and asthma were fairly constant in individuals above 18 years. During one year of observation, more than half of all patients had only been diagnosed in primary health care, with hypertension being the diagnosis with the largest proportion of patients only identified in primary health care (70.6\%).

Conclusion: The prevalence of common diseases in the population can be estimated by combining data gathered during consecutive years from primary care, specialist outpatient care and inpatient care. However, accuracy of disease prevalence is highly dependent on the quality of the data. The high prevalence of the six diagnoses analysed in this study calls for preventive action to minimize suffering and costs to society.

Keywords: Administrative databases, Primary care, Gender differences, Age differences, Epidemiology

\footnotetext{
* Correspondence: axelcefam@hotmail.com

${ }^{1}$ Centre for Family Medicine, Department of Neurobiology, Care Sciences and Society, Karolinska Institutet, Alfred Nobels Allé 12, 14183 Huddinge, Sweden ${ }^{2}$ Department of Public Health and Caring Sciences/ Section of Geriatrics, Uppsala University, Uppsala, Sweden

Full list of author information is available at the end of the article
} 


\section{Background}

Epidemiological data on the prevalence and incidence of diseases are valuable for making policy decisions and promoting evidence-based disease prevention and management. Prevalence can be assessed in several ways [1]. First, by self-reported presence of diseases, which may contain several uncertainties and result in different validity depending on the studied diagnosis. Second, by using or combining healthcare source data based on diagnosis records or on drug prescriptions but where individuals without prescribed drugs will be lost. Third, by the use of two or more data sources which could be combined by capture-recapture methods. Fourth, by population-based screenings which will identify new cases but will have lower validity in studies with low participation rates.

The establishment of the Swedish Hospital Discharge Register in 1964 has facilitated studies on the prevalence of diseases that require hospitalization [2,3]. The Swedish Hospital Discharge Register includes all hospitalizations from 1987 onwards as well as all outpatient consultations in hospitals from 2001 onwards. A number of studies using this register have showed that the quality of its data is high and the register has been widely used in many outcome studies $[4,5]$.

In recent years, the development of electronic medical records and administrative databases has facilitated studies on the prevalence and incidence of diseases in the total population of different regions [6,7]. The main advantages of these registers are their full coverage of healthcare consultations and that they are relatively easy and inexpensive to use. Disadvantages include possible bias in recording of diagnoses and variability in data quality [8].

In Stockholm County, with a total population of more than two million people, all diagnosis codes and reasons for hospitalizations and consultations in primary health care and specialist care are recorded and stored in a large administrative database. This comprehensive data collection enables epidemiological research in a large unselected population cohort. The primary aim of this study was to use these data to estimate the prevalence of six common diagnoses, namely diabetes mellitus, depression, anxiety disorders, hypertension, asthma, and chronic obstructive pulmonary disease (COPD) in the total population of Stockholm County. Furthermore, the distribution of these diagnoses across the different sectors of the healthcare system, i.e. primary health care (PC), specialist outpatient care (SOC) and inpatient care (IC), recorded during the last year of observation, 2011, was also determined.

\section{Methods}

Stockholm County has 2.1 million inhabitants, representing more than one-fifth of Sweden's entire population.
This area of Sweden includes the capital city of Stockholm and several other cities and towns, as well as large rural areas and a sparsely-populated archipelago. The Stockholm County Council is responsible for financing primary and secondary health care, mainly through taxes. Besides illegal immigrants, the general health insurance covers all residents. The majority of services are provided by County-owned facilities. However, during the last decade, more than $50 \%$ of primary care and approximately $8 \%$ of acute hospital care services have been outsourced to private providers, either through tender processes or managed patient choice [9]. Private providers are in contractual agreements with the County and are legally obliged to record diagnoses and file reports to the authorities just like public providers [10]. With the exception of very few private clinics that operate without subsidies in Stockholm, all consultations and diagnoses are recorded and stored in the so-called VAL, a central database. Besides consultations and diagnoses, VAL compiles and stores data on healthcare utilization and socio-demographics. The database has been used for healthcare planning, practice remuneration and quality assessment since the beginning of the 1980s, and its content, registration routines, and supporting software have improved over the years. It has previously been used as a source of information in a number of scientific studies, e.g. studies of hip fractures and its comorbidities [11,12], and Parkinson's disease [13]. As an indication for its accuracy and validity, VAL is used by the Council for updating the National Patient Register kept by the Swedish National Board of Health and Welfare (NBHW) as well as the annual benchmarking reports of the NBWH and the Swedish Association of Local Authorities and Regions [4].

VAL has more than 99\% coverage of hospital care. More specifically, for each hospital stay the VAL database contains a record of the provider unit, an encrypted patient identification number, age and sex, the type and length of the stay, up to ten diagnoses given, and ten interventions (primarily surgical procedures, transfusions, anaesthetic procedures). Since 1997, diagnoses have been coded according to WHO's International Classification of Diseases, $10^{\text {th }}$ edition (ICD-10) and procedures classified according to the Nordic Classification of Surgical Procedures (NCSP).

Reporting utilization in specialized ambulatory care, whether in hospital clinics or other locations, is also mandatory since the late 1990s. This includes reporting diagnoses (up to eight) for consultations by a physician, date, type of visit, and certain procedures performed. Also, nurse visits in homecare, visits to occupational or physical therapists as well as most other healthcare professionals are registered. VAL has more than $90 \%$ coverage of utilization in specialized ambulatory care. 
Storing data on primary care diagnoses in VAL has a shorter history. In 2003, a project to extract information on diagnoses (up to 15) from the electronic medical records, when available, was launched. It has been estimated that approximately $85 \%$ of all diagnoses in primary care are stored in VAL.

All data extracted from VAL were anonymised in the current study.

\section{Ethics}

All data we handled were anonymized and none of the numbers presented could be traced back to any individual. Management and analysis based on the VAL database is a part of continuous quality control of healthcare utilization in Stockholm county council. Research projects deemed as quality control are not subject to ethical research board decisions in Sweden.

\section{Study population}

The present study population included all living persons who resided in Stockholm County on December $31^{\text {st }}$ 2011 ( N = 2093 717). Demography of Stockholm County and number of doctor visits per person in 2011 are shown in Table 1. Residents who died or moved from the region during the five-year period of interest (2007-2011) were excluded. Data on all healthcare consultations in PC, SOC and IC between 2007 and 2011 were extracted from VAL.

\section{Major diagnosis groups}

The following ICD codes were used to define each major diagnosis group: diabetes mellitus E10-E14, depression F32-F33, anxiety disorders F40-F41, hypertension I10I15, asthma J45-J46, and chronic pulmonary respiratory disease (COPD) J41-J44, J47. The five-year prevalence of each diagnosis was calculated by dividing the number of persons with any of the diagnosis groups recorded at least once between January $1^{\text {st }} 2007$ and December $31^{\text {st }}$ 2011 with the total population number as for December 31st 2011. In a similar fashion, one-year prevalence of each diagnosis (2011) was calculated by dividing the number of persons with any of the diagnosis groups recorded at least once during 2011 with the total population number. The one-year- and five-year prevalence figures may be viewed as a period prevalence, especially for depression, and anxiety disorders.

\section{Statistical methods}

Standard descriptive statistics such as numbers and percentages out of the total population $(\mathrm{N})$ were used. Prevalence was presented as total/overall and was also stratified by age and sex. Statistical analysis and data management was performed using SAS software, version 9.3 (SAS Institute Inc., Cary, NC).

\section{Results}

\section{Demography of Stockholm county}

The population of Stockholm county was younger than in the rest of the country, with only $14.2 \%$ of the population being 65 years of age and older, and as many as $38.9 \%$ in the age group 18-44 years (Table 1).

\section{Prevalence of diagnosed diabetes mellitus}

In total, $5.3 \%$ of women and $7.1 \%$ of men in Stockholm were diagnosed with diabetes during the five-year period as shown in Table 2A. The highest prevalence was found among persons aged $75-84$ years, $23.1 \%$ among women and $31.9 \%$ among men. In total, $56 \%$ of all patients identified with a diabetes diagnosis during a five-year period were diagnosed during the last year of observation, 2011.

\section{Prevalence of diagnosed depression}

With the exception of children and adolescents (aged $0-17$ years) where few were diagnosed $(0.18 \%)$, a diagnosis of depression was common across all age groups in both men and women as shown in Table 2B. The highest five-year period prevalence of diagnosed depression was found among women aged between 45-64 years (12.7\%) and men aged 85 years and older (10.8\%). In total, 37\% of all patients identified with a depression diagnosis during a five-year period were diagnosed during the last year of observation, 2011.

Table 1 The demography and number of doctor visits in Stockholm county as of December 31, 2011

\begin{tabular}{|c|c|c|c|c|c|c|c|c|c|c|c|c|}
\hline \multirow[t]{2}{*}{ Age-groups } & \multicolumn{2}{|c|}{ Women 2011} & \multicolumn{2}{|c|}{ Doctor visits per woman } & \multicolumn{2}{|c|}{ Men 2011} & \multicolumn{2}{|c|}{ Doctor visits per man } & \multicolumn{2}{|c|}{ Total 2011} & \multicolumn{2}{|c|}{ Doctor visits per person } \\
\hline & $n$ & $\%$ & PC & SOC & $n$ & $\%$ & PC & SOC & $n$ & $\%$ & PC & SOC \\
\hline $0-17$ & 219612 & 20.8 & 1.62 & 0.77 & 231845 & 22.4 & 1.57 & 0.89 & 451457 & 21.6 & 1.59 & 0.83 \\
\hline $18-44$ & 403774 & 38.2 & 1.69 & 1.24 & 410537 & 39.6 & 0.94 & 0.73 & 814311 & 38.9 & 1.31 & 0.98 \\
\hline $45-64$ & 254622 & 24.1 & 2.13 & 1.49 & 255355 & 24.6 & 1.57 & 1.26 & 509977 & 24.4 & 1.85 & 1.38 \\
\hline $65-74$ & 94586 & 9.0 & 3.11 & 2.06 & 87093 & 8.4 & 3.02 & 2.22 & 181679 & 8.7 & 3.07 & 2.13 \\
\hline 75-84 & 52699 & 5.0 & 5.20 & 2.64 & 37948 & 3.7 & 5.26 & 3.01 & 90647 & 4.3 & 5.23 & 2.79 \\
\hline $85-$ & 31383 & 3.0 & 6.09 & 2.23 & 14263 & 1.4 & 6.46 & 2.89 & 45646 & 2.2 & 6.20 & 2.44 \\
\hline Total & 1056676 & 100 & 2.22 & 1.37 & 1037041 & 100 & 1.64 & 1.14 & 2093717 & 100 & 1.93 & 1.26 \\
\hline
\end{tabular}

$P C$ primary care, SOC specialist open care. 
Table 2 The prevalence and the percentage in the population (Dec. 2011) of six diagnosis groups in 2007-2011 in men, women and all inhabitants (total) in Stockholm county by age: A) diabetes mellitus (E10-E14), B) depression (F32-F33), C) anxiety disorders/phobia (F40-F41) D) hypertension (I10-I15), E) asthma and F) (J45-J46) chronic obstructive pulmonary disease (COPD) (J41-J44, J47)

\begin{tabular}{|c|c|c|c|c|c|c|c|c|}
\hline \multirow[t]{2}{*}{ Age-groups } & \multicolumn{2}{|c|}{ Women 2007-2011 } & \multicolumn{2}{|c|}{ Men 2007-2011 } & \multicolumn{2}{|c|}{ Total 2007-2011 } & \multicolumn{2}{|c|}{$\begin{array}{l}\text { Recorded diagnosis in } 2011 \\
\text { alone and in relation to thos } \\
\text { recorded between 2007-201 }\end{array}$} \\
\hline & $\mathbf{N}$ & $\%$ & $\mathrm{n}$ & $\%$ & $\mathrm{n}$ & $\%$ & n & $\%$ \\
\hline \multicolumn{9}{|c|}{ A) The prevalence of diagnosed diabetes mellitus. } \\
\hline $0-17$ & 676 & 0.3 & 852 & 0.4 & 1528 & 0.3 & 1229 & 80.4 \\
\hline $18-44$ & 4918 & 1.2 & 6221 & 1.5 & 11139 & 1.4 & 6700 & 60.1 \\
\hline $45-64$ & 16997 & 6.7 & 28212 & 11.0 & 45209 & 8.9 & 25290 & 55.9 \\
\hline $65-74$ & 14751 & 15.6 & 22230 & 25.5 & 36981 & 20.4 & 20828 & 56.3 \\
\hline $75-84$ & 12179 & 23.1 & 12123 & 31.9 & 24302 & 26.8 & 13228 & 54.4 \\
\hline 85- & 6417 & 20.4 & 3665 & 25.7 & 10082 & 22.1 & 4915 & 48.8 \\
\hline Total & 55938 & 5.3 & 73303 & 7.1 & 129241 & 6.2 & 72190 & 55.9 \\
\hline
\end{tabular}

B) The prevalence of diagnosed depression.

$\begin{array}{cccccccccc}0-17 & 570 & 0.3 & 265 & 0.1 & 835 & 0.2 & 640 & 76.6 \\ 18-44 & 40762 & 10.1 & 20131 & 4.9 & 60893 & 7.5 & 23834 & 39.1 \\ 45-64 & 32315 & 12.7 & 17403 & 6.8 & 49718 & 9.6 & 17724 & 35.6 \\ 65-74 & 8470 & 9.0 & 4080 & 4.7 & 12550 & 6.9 & 4313 & 34.4 \\ 75-84 & 5848 & 11.1 & 2344 & 6.2 & 8192 & 9.0 & 2993 & 36.5 \\ 85- & 3817 & 12.2 & 1121 & 7.9 & 4938 & 10.8 & 1592 & 32.2 \\ \text { Total } & 91782 & 8.7 & 45344 & 4.4 & 137126 & 6.6 & 51096 & 37.3\end{array}$

C) The prevalence of diagnosed anxiety disorders/phobia.

$\begin{array}{ccccccccc}0-17 & 1035 & 0.5 & 639 & 0.3 & 1674 & 0.4 & 925 & 55.3 \\ 18-44 & 34551 & 8.6 & 18816 & 4.6 & 53367 & 6.6 & 21919 & 41.1 \\ 45-64 & 20148 & 7.9 & 11421 & 4.5 & 31569 & 6.2 & 37.2 \\ 65-74 & 5265 & 5.6 & 2375 & 2.7 & 7640 & 4.2 & 2808 & 36.8 \\ 75-84 & 3380 & 6.4 & 1083 & 2.9 & 4463 & 4.9 & 1704 & 38.2 \\ 85- & 2203 & 7.0 & 474 & 3.3 & 2677 & 5.9 & 982 & 36.7 \\ \text { Total } & 66582 & 6.3 & 34808 & 3.4 & 101390 & 4.8 & 40096 & 39.5\end{array}$

D) The prevalence of diagnosed hypertension.

$\begin{array}{ccccccccc}0-17 & 115 & 0.1 & 121 & 0.1 & 236 & 0.1 & 71 & 30.1 \\ 18-44 & 5318 & 1.3 & 6047 & 1.5 & 11364 & 1.4 & 5715 & 50.3 \\ 45-64 & 41933 & 16.5 & 44822 & 17.5 & 86755 & 17.0 & 49645 & 57.2 \\ 65-74 & 38685 & 40.9 & 37568 & 43.1 & 76253 & 42.0 & 46191 & 60.6 \\ 75-84 & 31269 & 59.3 & 21367 & 56.3 & 52636 & 58.1 & 31832 & 60.5 \\ 85- & 20498 & 65.3 & 8467 & 59.4 & 28965 & 63.5 & 16052 & 55.4 \\ \text { Total } & 137817 & 13.0 & 118392 & 11.4 & 256209 & 12.2 & 149506 & 58.4\end{array}$

E) The prevalence of diagnosed asthma.

$\begin{array}{ccccccccc}0-17 & 17293 & 7.9 & 26184 & 11.3 & 43477 & 9.6 & 17924 & 41.2 \\ 18-44 & 21646 & 5.4 & 14950 & 3.6 & 36596 & 4.5 & 11945 & 32.6 \\ 45-64 & 15888 & 6.2 & 9167 & 3.6 & 25055 & 4.9 & 9142 & 36.5 \\ 65-74 & 6523 & 6.9 & 3327 & 3.8 & 9850 & 5.4 & 3793 & 38.5 \\ 75-84 & 3978 & 7.6 & 1691 & 4.5 & 5669 & 6.3 & 2217 & 39.1 \\ 85- & 1945 & 6.2 & 637 & 4.5 & 2582 & 5.7 & 1023 & 39.6 \\ \text { Total } & 67273 & 6.4 & 55956 & 5.4 & 123229 & 5.9 & 46044 & 37.4\end{array}$


Table 2 The prevalence and the percentage in the population (Dec. 2011) of six diagnosis groups in 2007-2011 in men, women and all inhabitants (total) in Stockholm county by age: A) diabetes mellitus (E10-E14), B) depression (F32-F33), C) anxiety disorders/phobia (F40-F41) D) hypertension (I10-I15), E) asthma and F) (J45-J46) chronic obstructive pulmonary disease (COPD) (J41-J44, J47) (Continued)

E) The prevalence of diagnosed COPD.

\begin{tabular}{ccccccccc}
$0-17$ & 335 & 0.2 & 434 & 0.2 & 769 & 0.2 & 455 & 59.2 \\
$18-44$ & 1001 & 0.3 & 748 & 0.2 & 1749 & 0.2 & 721 & 41.2 \\
$45-64$ & 6154 & 2.4 & 4685 & 1.8 & 10839 & 2.1 & 4910 & 45.3 \\
$65-74$ & 6875 & 7.3 & 5226 & 6.0 & 12101 & 6.7 & 6190 & 51.2 \\
$75-84$ & 5388 & 10.2 & 3741 & 9.9 & 9129 & 10.1 & 5027 & 55.1 \\
$85-$ & 2569 & 8.2 & 1435 & 10.1 & 4004 & 8.8 & 2094 & 52.3 \\
Total & 22322 & 2.1 & 16269 & 1.6 & 38591 & 1.8 & 19397 & 50.3 \\
\hline
\end{tabular}

The individuals with a reported diagnosis in 2011 are also shown in total and as percentage of the individuals with these diagnoses during the full period 2007-2011.

Prevalence of diagnosed anxiety disorders / phobia

More women than men were diagnosed with anxiety (6.3\% vs. $3.4 \%)$ as shown in Table 2 C. The highest prevalence was found among individuals aged between $18-44$ years. When stratified by sex, $8.6 \%$ of women and $4.6 \%$ of men were diagnosed of anxiety/phobia recorded. In total, $40 \%$ of all patients identified with an anxiety/ phobia diagnosis during a five-year period were diagnosed during the last year of observation, 2011.

\section{Prevalence of diagnosed hypertension}

As shown in Table 2D, $13.0 \%$ of women and $11.4 \%$ of men in Stockholm a hypertension diagnosis was recorded. An increase in diagnosed hypertension with advancing age, ranging between $0.05 \%$ in children and $63.5 \%$ in those aged 85 years and older was seen. Overall, hypertension was more common in women than men. In total, $58 \%$ of all patients identified with a hypertension diagnosis during a five-year period were diagnosed during the last year of observation, 2011.

\section{Prevalence of diagnosed asthma}

As shown in Table 2E, diagnosed asthma was equally common in men and women $(6.4 \%$ vs $5.4 \%)$ and most prevalent in children (9.6\%). In total, $37 \%$ of all patients identified with a asthma diagnosis during a five-year period were diagnosed during the last year of observation, 2011.

\section{Prevalence of diagnosed COPD}

Diagnosed COPD was more prevalent among persons aged 45 years and older with the highest prevalence in men and women aged between $75-84$ years $(10.1 \%)$ as shown in Table $2 \mathrm{~F}$. In total, $50 \%$ of all patients identified with a COPD diagnosis during a five-year period were diagnosed during the last year of observation, 2011.
Distribution of diagnoses recorded across different sectors of the healthcare system

The proportion of patients diagnosed with diabetes, depression, anxiety disorders, hypertension, asthma and COPD in PC, SOC, and/or IC during 2011 varied depending on the diagnosis group. A majority of the patients in all six diagnosis groups were only identified in only PC, with depression (56.5\%) and hypertension (70.6\%) being the most commonly recorded diagnoses in PC followed by diabetes mellitus (56.1\%), asthma (55.9\%), COPD (53.6\%), and anxiety/phobia (51.6\%). When comparisons in the distribution of all six diagnosis groups only in SOC were made, COPD was the most commonly recorded diagnosis (33.8\%). In IC, COPD was the most common diagnosis recorded of the six (15\%). It was uncommon to have a diagnosis recorded in all three health care sectors. Figures showing the distribution of diagnoses recorded in $\mathrm{PC}, \mathrm{SOC}$ and $\mathrm{IC}$ can be viewed, Additional file 1: Figure S1.

\section{Discussion}

The current study estimates prevalence of diagnosed common diseases in the total population in Stockholm County, a region with more than 2 million inhabitants, using recorded diagnoses in regional registers. The high prevalence of the six common diagnosis groups reported in this study calls for preventive action to be taken. Still, there may be people who are not yet diagnosed and population based health assessments have yielded individuals with newly diagnosed hypertension and diabetes $[1,14]$. With more than $30 \%$ of men and $20 \%$ of women aged between 75-84 years being diagnosed with diabetes during a five-year period, considerable amounts of health care resources will be needed. In addition, with $55 \%$ of all men and women in this age-group being diagnosed with hypertension, a considerable burden could be expected as this group would likely develop 
cardiovascular complications. The large amounts of younger patients diagnosed with these conditions, subsequently developing complications, may also pose a challenge for the future.

The fact that the population is large enables stratification by sex and age. Bearing in mind that approximately $20 \%$ of the inhabitants of Stockholm County are immigrants [15], the prevalence of common diseases in an urban population of a Western country can be used as a proxy for the prevalence of these diagnosed diseases in similar populations of other regions or countries.

The overall prevalence of diagnosed COPD was $1.8 \%$, which was higher than a previous study of COPD prevalence in a population living in a rural region of Sweden (1.2\%) that had a similar design [7]. The difference in prevalence could be due to more particles in the air in Stockholm, higher proportion of smokers or a higher awareness of COPD in recent years. Prevalence of diagnosed COPD increased dramatically among persons aged between 45-84 years whereas it decreased among persons aged 85 years and over which may be explained by the effect of smoking on longevity [16]. The opposite was observed for the prevalence of anxiety /phobia which was high in young adults aged between 18-44 years (6.6\%). A recent Swedish study, where a population based sample of 75-year-old persons was interviewed over a period of one month, reported that $3.7 \%$ had generalized anxiety disorder according to ICD10 [17], which is consistent with the five-year prevalence of $4.2 \%$ among persons aged between $65-74$ years of the total population of Stockholm County reported in this study. Another Swedish study reported that as much as $24 \%$ of the Swedish population aged 20-64 years fulfilled the criteria for anxiety and/or depression [18].

Diabetes is often regarded as equally common among men and women, although a male preponderance has been observed in those aged 45 years and over [19]. Wirehn et al. (2007) found an overall male preponderance in diagnosed diabetes prevalence $(4.6 \%$ in men vs $4.1 \%$ in women) [7] while in the current study an even larger male predominance in diagnosed diabetes prevalence was found ( $7.1 \%$ in men vs $5.3 \%$ in women). In a review (2001), Gale and Gillespie concluded that men may be more susceptible to physical inactivity and obesity than are women [20]. Overall prevalence of diagnosed diabetes was higher in the current study (6.2\%) than in earlier studies in Sweden (4.5\%) [7,21]. One explanation for the discrepancy may be the higher rate of immigrants living in Stockholm County [22]. A population-based study has shown that two thirds of the 60-year old diabetes patients are known [15].

The five-year period prevalence of diagnosed depression was high among adults, ranging between $9.0 \%$ and $12.2 \%$ in women and between 4.7 and $7.9 \%$ in men. The higher prevalence of depression among women than among men has been reported previously [23], and may be due to that women may be more active in seeking health care when they experience depressive symptoms. Also, the prevalence of diagnosed depression was lower among individuals younger than 65 years of age than those aged between 65-74 years which may be explained by lack of incentive to be sick-listed in the years following retirement. Persons with depression have been shown to have a higher risk for somatic diseases than non-depressed individuals [24], which may have had an effect on the diagnosed prevalence of all diagnosis groups in women in this study.

Studies of hypertension in the US have shown that the prevalence in the adult population (18 years of age and over) was nearly $30 \%[25,26]$, which was higher than that we reported in this study (12.2\%) implying there may be a large number of undiagnosed individuals in the total population of Stockholm County. This is in agreement with a screening study of 60 year-old persons from Stockholm which showed that newly diagnosed hypertension was more prevalent than already diagnosed hypertension [14]. The prevalence of hypertension is highly dependent on age [27], which was consistent with our findings. It has been previously shown that prevalence of hypertension is lower in women than in men until menopause, after which prevalence increases and reach levels observed in men [28,29]. Large scale population-based investigations are, however, still sparse and the true prevalence in the population is therefore not fully known, making the findings of the current valuable. Moreover, hypertension awareness, treatment and control vary greatly in different studies from around the world [30], and in populations of different countries studied following the same methodology [31].

In contrast to the other diagnosis groups, asthma appeared to affect children the most. Furthermore, diagnosed asthma was more common in boys than in girls and in women than men. The prevalence rates and gender differences are consistent with a recent review estimating the overall prevalence of asthma at 5-7\% in the total population and $8-10 \%$ in children [32]. Previous studies have also shown that women with asthma seek care more often than do men [33,34]. Asthma in children is often associated with rhinitis and eczema as well. The BAMSE birth cohort reported that 58\% of 12 year-old children had one, two or all these three conditions at some time [35].

Our study revealed important information on the prevalence of diagnosed common diseases in the population. It could be useful for the planning of healthcare needs, resource allocation and disease prevention. Access to electronic longitudinal data from primary healthcare may also provide unique opportunities for 
performing post-marketing comparative effectiveness research [2]. Some benefits include availability of large populations at a relatively low cost and shortening the time necessary to identify a sufficient number of patients with a specific diagnosed disease. They may also enable studies of patient groups that are usually omitted from randomized controlled trials, i.e. patients with comorbidities [36]. Recently, prescription data on individuals, using the same encrypted identification numbers as data from VAL, have been added to the database. This enables a unique possibility to link drug prescriptions to diagnoses and patient outcome.

It is important to emphasize that the frequency and diagnosis coverage may vary between different physicians, primary health care centres and diagnosis group [37]. Additionally, the reporting of diagnoses may change along with changes in the healthcare reimbursement system, however, no major changes occurred in the region during the course of this study. To achieve better prevalence estimates, data from $\mathrm{PC}$, SOC and IC could be used together and from consecutive years [7]. The applicability of our method may also vary between different settings. Health care systems vary widely across different regions and countries. More patients in Stockholm receive their care from specialists other than GPs, due to an proportionally smaller primary care sector compared with the UK [38].

Inclusion of only those who were alive at the end of the study period has likely introduced a survival bias as individuals who died during the five-year period were likely to have used considerably more healthcare resources than average. Consequently, the prevalence of diseases that are common among older persons, such as COPD, may have been underestimated. However, this is not a problem if the data are interpreted as point prevalences.

Most of the conditions encountered in PC are readily treatable, for example acute infections and inflammatory conditions, whereas others are chronic or relapsing and often non-acute such as diabetes mellitus, depression, anxiety disorders, hypertension, asthma, and chronic obstructive pulmonary disease (COPD). The diagnostic accuracy may also vary, depending on the disorder and the diagnostic criteria applied. For diabetes, highly valid diagnostic criteria make the disease easy to identify [39]. In the current study we did not make a distinction between Type I and Type II diabetes, as one of the most commonly used diagnosis codes in primary care is diabetes mellitus not otherwise specified. However, it is well known than Type II diabetes is more prevalent than Type I diabetes. While data on asthma, hypertension and diabetes diagnoses the diagnostic accuracy could be expected to be of high validity, data on COPD, anxiety/ phobia, and depression may not be as straightforward.
Stockholm County has seen more people moving in than moving out. Consequently, a slight underestimation in prevalence of the diagnostic groups may be expected as new inhabitants may have not yet lived in Stockholm long enough to have diagnoses recorded during the fiveyear period of interest. This may hold true for individuals aged between 18-44 years. However, this effect may have been balanced out by excluding those who died during the same period.

\section{Conclusion}

In conclusion, the prevalence of known and diagnosed diseases can be estimated using administrative health data registers. Whether a diagnosis is evaluated and recorded in primary care, specialist outpatient care or inpatient care, the diagnosed prevalence estimates are highly dependent on the quality of the diagnosis. It takes further validation studies to investigate if there are great discrepancies in diagnosis accuracy between different levels of care, and how that influences our overall knowledge of the existence of various patient groups. The high prevalence of the six diagnoses analysed in this study calls for preventive action to be taken to minimize suffering and costs to society.

\section{Additional file}

Additional file 1: Figure S1. Wenn diagrams of reported diagnoses: A) diabetes, C) depression, D) anxiety/phobia, E) hypertension F) asthma, and G) COPD. Primary care $=P C$, Specialist outpatient care $=S O C$, Inpatient care $=\mathrm{IC}$.

\section{Competing interests}

The authors of this manuscript have no conflict of interest to disclose.

\section{Authors' contributions}

$G L$ researched data, edited manuscript, contributed to discussion, ACC wrote manuscript, researched data, contributed to discussion. PW, BW, RZ, and UÖ edited manuscript, contributed to discussion. All authors read and approved the final manuscript.

\section{Funding}

This work was supported by the Stockholm County Council.

\section{Author details}

${ }^{1}$ Centre for Family Medicine, Department of Neurobiology, Care Sciences and Society, Karolinska Institutet, Alfred Nobels Allé 12, 14183 Huddinge, Sweden. ${ }^{2}$ Department of Public Health and Caring Sciences/ Section of Geriatrics, Uppsala University, Uppsala, Sweden. ${ }^{3}$ Neurogenetics Unit, Department of Molecular Medicine and Surgery, Karolinska Institutet, Solna, Sweden. ${ }^{4}$ Department of Psychiatry, Tiohundra AB, Norrtälje, Sweden. ${ }^{5}$ Public Healthcare Services Committee Administration, Stockholm County Council, Box 6909, SE- 10239 Stockholm, Sweden. ${ }^{6}$ Centre for Pharmacoepidemiology and Department of Laboratory Medicine, Division of Clinical Pharmacology, Karolinska University Hospital, Huddinge, Sweden. ${ }^{7}$ Medical Management Centre, Department of Learning, Informatics, Management and Ethics, Karolinska Institutet, Berzelius väg 3, SE-17177 Stockholm, Sweden.

Received: 22 October 2012 Accepted: 1 July 2013

Published: 18 July 2013 


\section{References}

1. Wandell PE, Johansson SE, Gafvels C, Hellenius ML, de Faire U, Sundquist J: Estimation of diabetes prevalence among immigrants from the Middle East in Sweden by using three different data sources. Diabetes Metab 2008, 34(4 Pt 1):328-333.

2. Rodriguez EM, Staffa JA, Graham DJ: The role of databases in drug postmarketing surveillance. Pharmacoepidemiol Drug Saf 2001, 10(5):407-410.

3. Sweden S: Statistical yearbook of Sweden 2011. Stockholm: Statistics Sweden; 2010.

4. Ludvigsson JF, Andersson E, Ekbom A, Feychting M, Kim JL, Reuterwall C, Heurgren M, Olausson PO: External review and validation of the Swedish national inpatient register. BMC Publ Health 2011, 11:450.

5. Rosen M: National health data registers: a Nordic heritage to public health. Scand J Public Health 2002, 30(2):81-85.

6. Nilsson G, Ahlfeldt H, Strender LE: Textual content, health problems and diagnostic codes in electronic patient records in general practice. Scand J Prim Health Care 2003, 21(1):33-36.

7. Wirehn AB, Karlsson HM, Carstensen JM: Estimating disease prevalence using a population-based administrative healthcare database. Scand J Public Health 2007, 35(4):424-431.

8. Sorensen HT, Sabroe S, Olsen J: A framework for evaluation of secondary data sources for epidemiological research. Int J Epidemiol 1996, 25(2):435-442.

9. Ekman I, Wolf A, Olsson LE, Taft C, Dudas K, Schaufelberger M, Swedberg K: Effects of person-centred care in patients with chronic heart failure: the PCC-HF study. Eur Heart J 2012, 33(9):1112-1119.

10. Burstrom B: Will Swedish healthcare reforms affect equity? BMJ 2009, 339:b4566.

11. Lofgren S, Ljunggren $G$, Brommels M: No ticking time bomb: hospital utilisation of 28,528 hip fracture patients in Stockholm during 1998-2007. Scand J Public Health 2010, 38(4):418-425.

12. Rydholm A, Ljunggren $G$, Grafström $M$, Strömberg L: Dementia, delirium and other co-morbid conditions in acute hip fracture care - traditions, attitudes and local policies rather than actual state guide diagnose making? Vårdi Norden 2005, 25(4):25-29.

13. Lokk J, Borg S, Svensson J, Persson U, Ljunggren G: Drug and treatment costs in Parkinson's disease patients in Sweden. ActaNeurol Scand 2012, 125(2):142-147.

14. Carlsson AC, Wandell PE, de Faire U, Hellenius ML: Prevalence of hypertension in immigrants and Swedish-born individuals, a cross-sectional study of 60-year-old men and women in Sweden. J Hypertens 2008, 26(12):2295-2302.

15. Wandell PE, Carlsson AC, de Faire U, Hellenius ML: Prevalence of blood lipid disturbances in Swedish and foreign-born 60-year-old men and women in Stockholm, Sweden. NutrMetab Cardiovasc Dis 2011, 21(3):173-181.

16. Carlsson AC, Theobald $H$, Wandell PE: Health factors and longevity in men and women: a 26-year follow-up study. Eur J Epidemiol 2010, 25(8):547-551.

17. Nilsson J, Ostling S, Waern M, Karlsson B, Sigstrom R, Guo X, Skoog I: The 1-month prevalence of generalized anxiety disorder according to DSM-IV, DSM-V, and ICD-10 among nondemented 75-year-olds in Gothenburg, Sweden. Am J Geriatr Psychiatry 2012, 20(11):963-972.

18. Wallerblad A, Moller J, Forsell Y: Care-seeking pattern among persons with depression and anxiety: a population-based study in Sweden. Int I Family Med 2012, 2012:895425.

19. Wandell PE, Gafvels C: Patients with type 2 diabetes aged $35-64$ years at four primary health care centres in Stockholm County, Sweden. Prevalence and complications in relation to gender and socio-economic status. Diabetes Res Clin Pract 2004, 63(3):195-203.

20. Gale EA, Gillespie KM: Diabetes and gender. Diabetologia 2001, 44(1):3-15.

21. Jansson SP, Andersson DK, Svardsudd K: Prevalence and incidence rate of diabetes mellitus in a Swedish community during 30 years of follow-up. Diabetologia 2007, 50(4):703-710.

22. Wandell PE, Carlsson A, Steiner KH: Prevalence of diabetes among immigrants in the Nordic countries. Curr Diabetes Rev 2010, 6(2):126-133.

23. Patten SB, Stuart HL, Russell ML, Maxwell CJ, Arboleda-Florez J: Epidemiology of major depression in a predominantly rural health region. Soc Psychiatry Psychiatr Epidemiol 2003, 38(7):360-365.

24. Andersson D, Magnusson H, Carstensen J, Borgquist L: Co-morbidity and health care utilisation five years prior to diagnosis for depression. A register-based study in a Swedish population. BMC Publ Health 2011, 11:552.

25. Egan BM, Zhao $Y$, Axon RN: US trends in prevalence, awareness, treatment, and control of hypertension, 1988-2008. JAMA 2010, 303(20):2043-2050.
26. Kearney PM, Whelton M, Reynolds K, Muntner P, Whelton PK, He J: Global burden of hypertension: analysis of worldwide data. Lancet 2005, 365(9455):217-223

27. Joffres MR, Hamet P, MacLean DR, L'Italien GJ, Fodor G: Distribution of blood pressure and hypertension in Canada and the United States. Am J Hypertens 2001, 14(1 Pt 1):1099-1105.

28. Mancia G, De Backer G, Dominiczak A, Cifkova R, Fagard R, Germano G, Grassi G, Heagerty AM, Kjeldsen SE, Laurent S, et al: 2007 Guidelines for the management of arterial hypertension: The Task Force for the Management of Arterial Hypertension of the European Society of Hypertension (ESH) and of the European Society of Cardiology (ESC). Eur Heart J 2007, 28(12):1462-1536.

29. Vasan RS, Beiser A, Seshadri S, Larson MG, Kannel WB, D'Agostino RB, Levy D: Residual lifetime risk for developing hypertension in middle-aged women and men: the Framingham heart study. JAMA 2002, 287(8):1003-1010.

30. Marques-Vidal P, Tuomilehto J: Hypertension awareness, treatment and control in the community: is the 'rule of halves' still valid? J Hum Hypertens 1997, 11(4):213-220.

31. Wolf-Maier K, Cooper RS, Banegas JR, Giampaoli S, Hense HW, Joffres M, Kastarinen M, Poulter N, Primatesta P, Rodriguez-Artalejo F, et al: Hypertension prevalence and blood pressure levels in 6 European countries, Canada, and the United States. JAMA 2003, 289(18):2363-2369.

32. Anandan C, Nurmatov $U$, van Schayck OC, Sheikh A: Is the prevalence of asthma declining? Systematic review of epidemiological studies. Allergy 2010, 65(2):152-167.

33. Osborne ML, Vollmer WM, Linton KL, Buist AS: Characteristics of patients with asthma within a large HMO: a comparison by age and gender. Am J Respir Crit Care Med 1998, 157(1):123-128.

34. Weiner P, Magadle R, Massarwa F, Beckerman M, Berar-Yanay N: Influence of gender and inspiratory muscle training on the perception of dyspnea in patients with asthma. Chest 2002, 122(1):197-201.

35. Ballardini N, Kull I, Lind T, Hallner E, Almqvist C, Ostblom E, Melen E, Pershagen G, Lilja G, Bergstrom A, et al: Development and comorbidity of eczema, asthma and rhinitis to age 12: data from the BAMSE birth cohort. Allergy 2012, 67(4):537-544.

36. Wandell PE, Carlsson AC, Sundquist K, Johansson SE, Sundquist J: Total mortality among levothyroxine-treated women with atrial fibrillation in Swedish primary health care. Int J Cardiol 2011, 152(1):147-148.

37. Hjerpe P, Merlo J, Ohlsson H, Bengtsson Bostrom K, Lindblad U: Validity of registration of ICD codes and prescriptions in a research database in Swedish primary care: a cross-sectional study in Skaraborg primary care database. BMC Med Inform Decis Mak 2010, 10:23.

38. Forrest CB: Primary care in the United States: primary care gatekeeping and referrals: effective filter or failed experiment? BMJ 2003, 326(7391):692-695.

39. Nazir A, Papita R, Anbalagan VP, Anjana RM, Deepa M, Mohan V: Prevalence of diabetes in Asian Indians based on glycated hemoglobin and fasting and 2-h post-load (75-g) plasma glucose (CURES-120). Diabetes Technol Ther 2012, 14(8):665-668.

\section{doi:10.1186/1471-2458-13-670}

Cite this article as: Carlsson et al:: High prevalence of diagnosis of diabetes, depression, anxiety, hypertension, asthma and COPD in the total population of Stockholm, Sweden - a challenge for public health. BMC Public Health 2013 13:670.

\section{Submit your next manuscript to BioMed Central and take full advantage of:}

- Convenient online submission

- Thorough peer review

- No space constraints or color figure charges

- Immediate publication on acceptance

- Inclusion in PubMed, CAS, Scopus and Google Scholar

- Research which is freely available for redistribution 